\title{
Occupational exposure to magnetic fields in relation to mortality from brain cancer among electricity generation and transmission workers
}

\author{
J M Harrington, D I McBride, T Sorahan, G M Paddle, $M$ van Tongeren
}

\begin{abstract}
Objective-To investigate whether the risks of mortality from brain cancer are related to occupational exposure to magnetic fields.

Methods-A total of 112 cases of primary brain cancer (1972-91) were identified from a cohort of 84018 male and female employees of the (then) Central Electricity Generating Board and its privatised successor companies. Individual cumulative occupational exposures to magnetic fields were estimated by linking available computerised job history data with magnetic field measurements collected over 675 person-workshifts. Estimated exposure histories of the case workers were compared with those of 654 control workers drawn from the cohort (nested case-control study), by means of conditional logistic regression.

Results-For exposure assessments based on arithmetic means, the risk of mortality from brain cancer for subjects with an estimated cumulative exposure to magnetic fields of 5.4-13.4 $\mu \mathrm{T}$.y $v$ subjects with lower exposures $(0 \cdot 0-5 \cdot 3 \mu \mathrm{T} . \mathrm{y})$ was $1 \cdot 04$ (95\% confidence interval (95\% CI) 0.60 to $1 \cdot 80$ ). The corresponding relative risk in subjects with higher exposures ( $\geqslant 13.5 \mu$ T.y) was 0.95 (95\% CI 0.54 to 1.69). There was no indication of a positive trend for cumulative exposure and risk of mortality from brain cancer either when the analysis used exposure assessments based on geometric means or when the analysis was restricted to exposures received within five years of the case diagnosis (or corresponding period for controls).

Conclusions-Although the exposure categorisation was based solely on recent observations, the study findings do not support the hypothesis that the risk of brain cancer is associated with occupational exposure to magnetic fields.
\end{abstract}

(Occup Environ Med 1997;54:7-13)

Keywords: electromagnetic fields; brain cancer; electrical workers

Concern about the possible risks of malignancy associated with occupational exposure to extremely low frequency electromagnetic fields began in 1982 with a report which linked the statement of "electrical occupation" on death certificates in Washington State to an increased risk of leukaemia. ${ }^{1}$ Three years later, a similar study by $\operatorname{Lin}$ et $a l^{2}$ extended the tumour sites of interest to the brain. Since that time, many reports have appeared supporting the link between "electrical or electronic workers" and an increased risk of leukaemia, or brain cancer, or both. Also, cohort and case control studies have been published for relevant industries.

Recent reviews of the literature have highlighted much inconsistency between the studies, but overall, a modest increase of risk for leukaemia and brain cancer has been reported and the list of suspect cancer sites now includes male breast cancer and malignant melanoma. ${ }^{3}$ Many of the earlier studies have been criticised for their design limitations - in particular, validity of exposure assessment, sample size, multiple analyses, and failure to control for possible confounding factors. Recent studies, notably those by Floderus et $a l,{ }^{4}$ Sahl et $a l^{5}{ }^{5}$ Thériault et $a l,{ }^{6}$ and Savitz and Loomis ${ }^{7}$ have made serious attempts to counter these shortcomings. However, these studies still leave cause for debate as to whether the links between exposure and disease are causal because findings have been inconsistent, and the increases in risk have, by and large, been modest. ${ }^{8}$

The study reported in this paper has been developed from a cohort of electricity generation and transmission workers of the (then) Central Electricity Generating Board (CEGB) of England and Wales. The CEGB was privatised in 1990 and then comprised four successor companies-three generation companies Nuclear Electric, National Power, and Powergen) and one transmission company (National Grid Company).

Initial analysis of standardised mortality ratios (SMRs) for the tumour sites of interest did not indicate any significant increases but the cohort had, by 1993, experienced over 100 deaths from brain cancer. This number was considered sufficient to undertake a nested case-control study within the cohort.

\section{Materials and methods}

STUDY POPULATION

The cohort consisted of 84018 men and women employed for at least six months between 1 April 1972 and 31 March 1984. Employees in some regions did not enter the study in 1972 because entrance to the cohort depended on the date of computerisation of the payroll for each region. All employees 
were, however, included by 1 April 1979 . Information on vital status was obtained through the Department of Social Security (DSS) and death certificates were provided by the Office of Population, Censuses and Surveys (OPCS). Of 84018 people whose details were submitted to the DSS, all but 24 were traced by a combination of computerised and manual searching. A total of 10010 people were identified as having died at the time of the last inquiry; there was no record of death for the remaining 73984 . Current estimates suggest that the DSS route may miss $1 \%$ of deaths.

Death certificates have been obtained from OPCS for all but $334(3.3 \%)$ of the 10010 people notified as having died. Among the 10010 deaths occurring in the cohort to 31 December 1991, 176 primary or secondary brain cancers were identified from death certificate information. Verification was obtained through the National Cancer Registration and a diagnosis of primary brain cancer was confirmed in 112 cases. These formed the basis of the study; the remainder were confirmed as secondary tumours.

Six controls from the cohort were chosen for each case after considering power calculations and the logistics of obtaining exposure data. Controls were selected to be the same sex as the case and alive at the time of death of the case. The six study subjects satisfying these conditions and whose dates of birth were nearest to those of the case were then selected as controls. Cases were allowed to be selected as controls in earlier risk sets and control subjects could be selected for more than one case. One control was later discovered to have been selected in error and was deleted. A further 17 controls had no period of employment before the date of diagnosis of the case. Consequently, at the date of diagnosis, they were not in the risk set and were excluded from the study. The final number of study subjects comprised 112 cases and 654 controls.

\section{EXPOSURE ASSESSMENT}

\section{Contemporary exposure measurements}

Exposure was assessed by combining information on measured exposures from the survey of staff in the United Kingdom electricity supply industry reported by Merchant et $a l^{9}$ with the recorded job history. In that survey, 258 workers from various jobs and locations were asked to wear a monitor continuously for a week. Also, seven research and development staff were monitored for seven days in a pilot survey. Two types of monitors were used, a monitor produced by the Institute de Recherché d'Hydro, Quebec (IREQ) and a similar version produced by Positron Industries. Both monitors were sensitive primarily to $50 \mathrm{~Hz}$ and recorded root mean squared power frequency magnetic fields in three orthogonal directions at intervals of 60 seconds. Due to monitor failures measurement records with more than three days of valid data were available for only 221 workers.

During the period of data collection, employees kept a diary noting times they were (a) at home in bed; (b) up and about at home; (c) out; (d) travelling to work; (e) at work; and (f) not wearing monitors. The current study was concerned with workplace exposures and therefore only the exposures measured at work were used. Results from the power frequency magnetic fields measurements for non-occupational activities have been reported by Merchant et al. ${ }^{10}$

Measurements were obtained from four different types of site; power stations, transmission substations $(275 \mathrm{kV}$ and $400 \mathrm{kV})$ and offices, distribution substations $(<132 \mathrm{kV})$ and offices, and offices not on electrical sites. All workers were classified into one of 15 job groups. For each person, exposure was assessed as the mean of all the measurements. As the individual mean exposures were log normally distributed, time weighted geometric mean exposure (TW-GM) for each job category was calculated as well as time weighted arithmetic mean exposure (TW-AM). The figure shows mean exposures (with ranges) and illustrates variation in exposures for each of the 11 job groupings relevant to this mortality study; it shows the considerable overlap that exists between the jobs. The figure summaries data relating to 151 workers who contributed data from a total of 675 person-workshifts.

\section{Combining measurements and job histories}

The computerised work histories of all cases and controls were coded in terms of the 11 job groups relevant to this study (data from the regional electricity companies were excluded) by two ex-CEGB electrical engineers with long experience in the industry. The job title for each employee had been recorded on entry to the cohort and information on subsequent occupations (to the end of March 1984) was obtained from the payroll file supplied by the regional personnel departments of the CEGB.

The two assessors worked independently and blind to case or control status. They considered the likely activities of each job group identified by the exposure survey and selected the category which corresponded most closely with the working environment of each job held by a person. A pilot assignment session was carried out on a random selection of people to clarify procedures for the assessors and to formulate criteria for making the assessments. After the first main session there was $76 \%$ concordance between the assessors. The differences in coding were resolved by consensus between the two assessors. For five cases and 17 controls, exposure assessments were available for some but not all periods of employment history. For these subjects, the preceding assessment (or after assessment if the former was unavailable) was assumed to apply to the unclassifiable part of the employment history. There remained 86 people (18 cases and 68 controls) for whom there was insufficient data on the employment history to assign an exposure. Study subjects were unclassified because either no information on job history was available (nine cases and 31 controls), or the only information supplied was foreman (three cases 
Survey of assessment of magnetic fields of 11 job categories. ${ }^{9}$

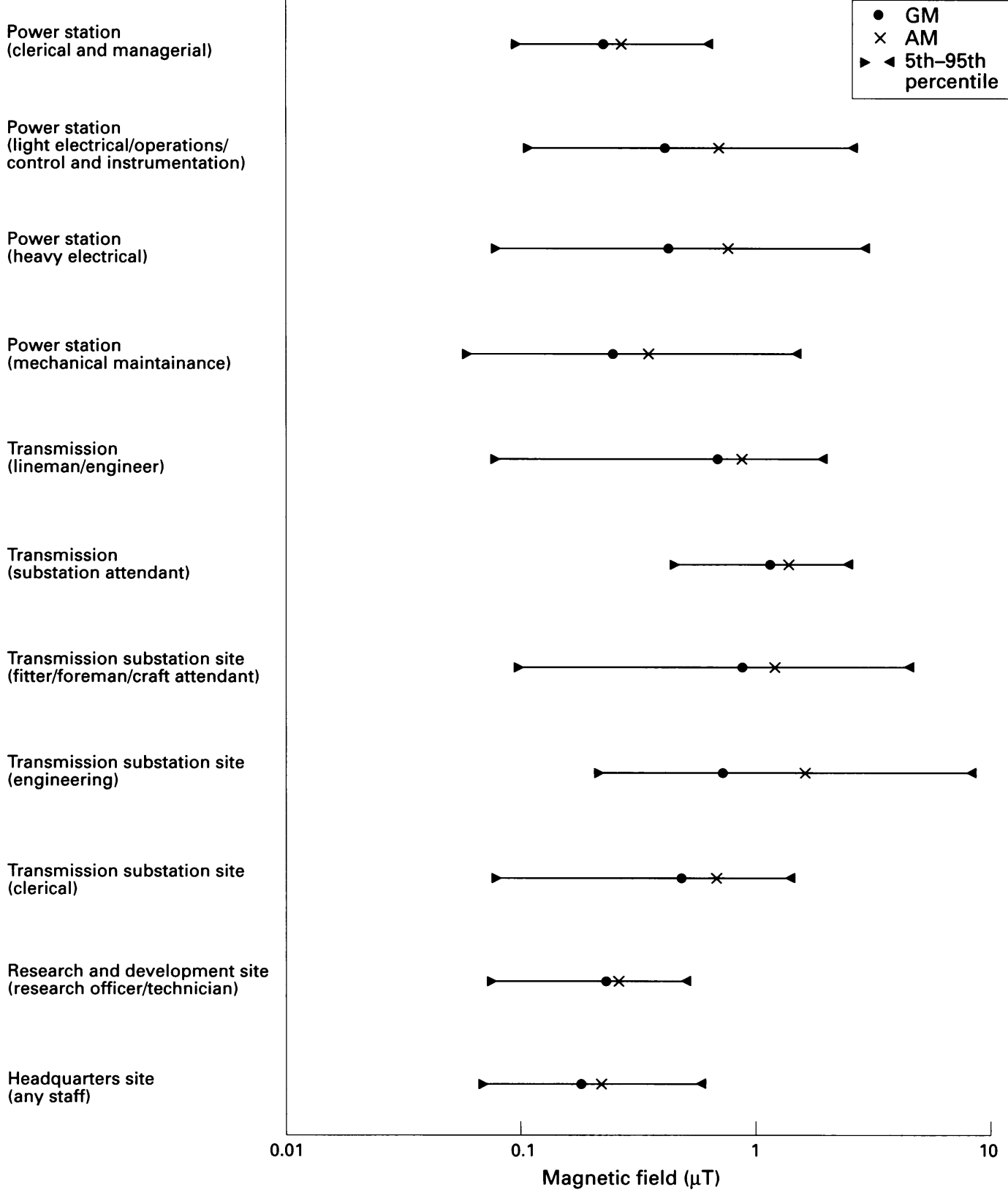

and 16 controls), or job titles could not be related to one of the 11 job categories used in the study (six cases and 21 controls).

For the case-control analyses, cumulative exposure was estimated in six different ways. First cumulative exposure was calculated by multiplying the TW-AM exposures with the duration of employment (in years) for each job described in the computerised job history. Employment histories for all members of each case-control set were considered until the date of diagnosis of brain cancer for the case. These calculations were then repeated with TW-GM exposures. For most members of the cohort, job histories were not known for the time between the date of joining the industry and the date of entry to the study file (date of computerisation). However, for a subcohort of 16591 members these data were available. Analysis showed that for about $60 \%$ of employees there were no job changes during this time and in a further $30 \%$ there was only one job change. Consequently for the second pair of cumulative exposure estimates (AM and GM) it was assumed that the job recorded at the date of computerisation had been followed in all earlier periods of employment with the participating industries. Finally, to enable comparison with the study of Thériault et al, cumulative exposures for cases and matched controls were calculated only for the five years before the case diagnosis. Computerised job histories were not available after March 1984. Consequently, the later exposure estimates were only calculated for those 51 case-control sets in which the case was diagnosed before April 1984.

For each exposure metric, three levels of cumulative exposure were considered (together with an unclassifiable category). The cut off values for the three exposure groups were chosen to be those values of $\mu \mathrm{T}$.y given to one place of decimals which were closest to the tertile values for all study subjects. This procedure was chosen blind to any knowledge of study findings. 
Table 1 List of potential confounding exposures

1 Ozone in rectifier houses and electrostatic precipitators

2 Boiler dosing and treatment chemicals-caustic soda, hydrazine, trisodium phosphate, ammonia, cyclohexylamine, sodium nitrate, borax, fluorescein

3 Boiler cleaning - hydrochloric acid, hydrofluoric acid, citric acid, inhibitors, phosphoric acid, adipic acid

Water treatment chemicals-sulphuric acid, sodium hydroxide, hydrochloric acid resins, lime soda process, flocculating agents, chlorine, hypochlorite, ferric sulphate

Insulation materials-asbestos, man made mineral fibres, calcium silicate

Mineral oils and greases

7 Machining oils and cutting fluids, biocides, detergents

8 Boiler deposits-from coal and oil firing including vanadium and other heavy metals

9 Combustion products-pulverised fuel ash, oil residues, flue gas, mill fire gases

10 Fire resistant fluids (phosphate esters)

11 Fume-welding, cutting, burning, soldering, grinding, chromium fume, cadmium

12 Solvents and solvent cleaners-1,1,1 trichlorethane, trichloroethylene, benzene

13 Carbon tetrachloride, dichloromethane, hydrocarbons - paraffin, aromatic

14 Solvent and detergent mixtures

15 Fuels - heavy and light oil, gas oil, coal and pulverised fuel, silica in coal, orimulsion

16 Mercury metal

17 Proprietary solvent mixtures-Igema fluids

18 Analytical reagents including O-toluidine

19 Adhesives - solvent based, isocyanate based, rubber solvents

20 Ionising radiation

20 Ionising radiation

21 Methanol in bulk

23 Paint and paint solvent vapours, lead, thinners, creosote 24 Wood dust exposure (table 1) on the other. Each cell was categorised as ever exposed (or likely exposed), never exposed (not or hardly exposed), or unclassifiable (possibly exposed).

\section{STATISTICAL PROCEDURES}

The estimated cumulative exposures of cases and controls were compared with conditional logistic regression applied to matched sets. ${ }^{13}$ The statistical significance of any trend in risk across the three exposure categories was assessed by ignoring the unclassifiable cases and controls and treating cumulative exposure as a continuous variable coded 1,2 , or 3 for the three levels of exposure.

\section{Results}

Table 2 shows odds ratios (ORs) for brain cancer by levels of cumulative exposure to electromagnetic fields for periods of employment detailed in the computerised job histories. The ORs are shown with and without adjustment for four different periods of year of hire. The trend analyses are carried out separately; table 2 thus summarises eight separate analyses. There are non-significant negative trends of risk with levels of cumulative exposure. Cases featured more prominently than controls in the unclassifiable study subjects.

Table 3 shows ORs for brain cancer by levels of cumulative exposure to electromagnetic fields in which the first recorded computerised

Table 2 Relative risks of brain tumours in relation to cumulative exposure to electromagnetic fields based on computerised job history

\begin{tabular}{|c|c|c|c|c|c|}
\hline $\begin{array}{l}\text { Basis of } \\
\text { hygiene } \\
\text { assessments }\end{array}$ & $\begin{array}{l}\text { Cumulative } \\
\text { exposure } \\
(\mu T . y)\end{array}$ & Cases & Controls & OR $(95 \% C I)$ & ORt $(95 \% C I)$ \\
\hline $\mathbf{A M}$ & $\begin{array}{l}0 \cdot 0- \\
3 \cdot 1- \\
\geqslant 6 \cdot 0 \\
\text { Unclassifiable } \\
\text { Trend } \neq\end{array}$ & $\begin{array}{l}30 \\
37 \\
27 \\
18\end{array}$ & $\begin{array}{r}193 \\
192 \\
201 \\
68\end{array}$ & $\begin{array}{l}1.0 \\
1.30(0.75 \text { to } 2.23) \\
0.91(0.51 \text { to } 1.63) \\
1.84(0.93 \text { to } 3.64) \\
0.89(0.67 \text { to } 1.19)\end{array}$ & $\begin{array}{l}1.0 \\
1.42(0.82 \text { to } 2.47) \\
0.97(0.53 \text { to } 1.78) \\
2.18^{\star}(1.08 \text { to } 4.39) \\
0.929(0.68 \text { to } 1.24)\end{array}$ \\
\hline GM & $\begin{array}{l}0.0- \\
2 \cdot 3- \\
\geqslant 3 \cdot 7 \\
\text { Unclassifiable } \\
\text { Trend } \neq\end{array}$ & $\begin{array}{l}29 \\
41 \\
24 \\
18\end{array}$ & $\begin{array}{r}190 \\
183 \\
213 \\
68\end{array}$ & $\begin{array}{l}1.0 \\
1.54(0.87 \text { to } 2.71) \\
0.77(0.40 \text { to } 1.47) \\
1.88(0.93 \text { to } 3.79) \\
0.80(0.58 \text { to } 1.10)\end{array}$ & $\begin{array}{l}1.0 \\
1.65(0.91 \text { to } 3.00) \\
0.87(0.43 \text { to } 1.78) \\
2.24^{\star}(1.08 \text { to } 4.64) \\
0.84(0.59 \text { to } 1.18)\end{array}$ \\
\hline
\end{tabular}

$\star P<0.05$.

†After adjustment for four periods of year of hire $(<1955,1955-64,1965-74, \geqslant 1975)$.

$\neq$ Increase in risk per unit change in exposure level. The three levels are coded 1,2 , or 3 and the variable is treated as continuous.

IORs for the year of hire variable were as follows: $<1955$, OR $=1.0 ; 1955-64$, OR $=1.66$ (95\% CI 0.97 to 2.83$)$; 1965-74,

ORs for the year of hire variable were as follows: $<1955, \mathrm{OR}=1 \cdot 0 ; 1955-64$,
$\mathrm{OR}=0.92(95 \% \mathrm{CI} 0.50$ to 1.67$) ; \geqslant 1975, \mathrm{OR}=1.97(95 \% \mathrm{CI}=0.92$ to $4 \cdot 18)$.

Table 3 Relative risks of brain tumours in relation to cumulative exposure to electromagnetic fields based on computerised job histories and estimates for earlier periods of employment

\begin{tabular}{|c|c|c|c|c|c|}
\hline $\begin{array}{l}\text { Basis of } \\
\text { hygiene } \\
\text { assessments }\end{array}$ & $\begin{array}{l}\text { Cumulative } \\
\text { exposure } \\
(\mu T . y)\end{array}$ & Cases & Controls & OR $(95 \% C I)$ & $O R^{*}(95 \% C I)$ \\
\hline AM & $\begin{array}{l}0 \cdot 0- \\
5 \cdot 4- \\
\geqslant 13 \cdot 5 \\
\text { Unclassifiable } \\
\text { Trendt }\end{array}$ & $\begin{array}{l}32 \\
32 \\
30 \\
18\end{array}$ & $\begin{array}{r}196 \\
194 \\
196 \\
68\end{array}$ & \multirow{3}{*}{$\begin{array}{l}1.0 \\
1.04(0.60 \text { to } 1.80) \\
0.95(0.54 \text { to } 1.69) \\
1.72(0.87 \text { to } 3.42) \\
0.88(0.66 \text { to } 1.19) \\
1.0 \\
1.81(0.46 \text { to } 1.42) \\
0.95(0.53 \text { to } 1.69) \\
1.58(0.80 \text { to } 3.14) \\
0.89(0.66 \text { to } 1.19)\end{array}$} & \multirow{3}{*}{$\begin{array}{l}1.0 \\
1.10(0.61 \text { to } 1.99) \\
0.98(0.51 \text { to } 1.87) \\
1.98(0.96 \text { to } 4.11) \\
0.86 \ddagger(0.62 \text { to } 1.21) \\
1.0 \\
0.81(0.41 \text { to } 1.58) \\
0.97(0.47 \text { to } 2.02) \\
1.79(0.84 \text { to } 3.83) \\
0.85(0.58 \text { to } 1.25)\end{array}$} \\
\hline \multirow[t]{2}{*}{ GM } & $\begin{array}{l}0 \cdot 0- \\
4 \cdot 1- \\
\geqslant 8 \cdot 0 \\
\text { Unclassifiable } \\
\text { Trendf }\end{array}$ & $\begin{array}{l}34 \\
28 \\
32 \\
18\end{array}$ & $\begin{array}{r}193 \\
199 \\
194 \\
68\end{array}$ & & \\
\hline & Total & 112 & 654 & & \\
\hline
\end{tabular}

*After adjustment for four periods of year of hire $(<1955,1955-64,1965-74, \geqslant 1975)$.

$\dagger$ Increase in risk per unit change in exposure level. The three levels are coded 1,2 , or 3 and the variable is treated as continuous.

FORs for the year of hire variable were as follows: $<1955, \mathrm{OR}=1.0 ; 1955-64, \mathrm{OR}=1.64$ (95\% CI 0.96 to 2.79$) ; 1965-74$,

OR $=0.94(95 \%$ CI 0.50 to 1.74$) ; \geqslant 1975, O R=1.97(95 \% \mathrm{CI}=0.87$ to 4.45$)$. 
Table 4 Relative risks of brain tumours in relation to cumulative exposure to electromagnetic fields for the five year period preceding diagnosis of the case

\begin{tabular}{|c|c|c|c|c|c|}
\hline $\begin{array}{l}\text { Basis of } \\
\text { hygiene } \\
\text { assessments }\end{array}$ & $\begin{array}{l}\text { Cumulative } \\
\text { exposure } \\
(\mu T . y)\end{array}$ & Cases & Controls & OR $(95 \% C I)$ & $O R^{\star}(95 \% C I)$ \\
\hline AM & $\begin{array}{l}0 \cdot 0- \\
1 \cdot 6- \\
\geqslant 3 \cdot 7 \\
\text { Unclassifiable } \\
\text { Trend } \dagger\end{array}$ & $\begin{array}{l}16 \\
13 \\
11 \\
11\end{array}$ & $\begin{array}{l}87 \\
80 \\
86 \\
36\end{array}$ & \multirow{3}{*}{$\begin{array}{l}1.0 \\
0.85(0.38 \text { to } 1.92) \\
0.71(0.31 \text { to } 1.62) \\
1.76(0.72 \text { to } 4.29) \\
0.83(0.55 \text { to } 1.26) \\
1.0 \\
0.69(0.30 \text { to } 1.62) \\
0.79(0.35 \text { to } 1.78) \\
1.72(0.71 \text { to } 4.17) \\
0.86(0.56 \text { to } 1.31)\end{array}$} & \multirow{3}{*}{$\begin{array}{l}1.0 \\
0.76(0.33 \text { to } 1.74) \\
0.59(0.25 \text { to } 1.38) \\
1.76(0.71 \text { to } 4.34) \\
0.78 \ddagger(0.51 \text { to } 1.19) \\
1.0 \\
0.63(0.27 \text { to } 1.47) \\
0.66(0.29 \text { to } 1.53) \\
1.73(0.70 \text { to } 4.25) \\
0.80(0.52 \text { to } 1.24)\end{array}$} \\
\hline GM & $\begin{array}{l}0 \cdot 0- \\
1 \cdot 2- \\
\geqslant 2 \cdot 0 \\
\text { Unclassifiable } \\
\text { Trend } \dagger\end{array}$ & $\begin{array}{l}17 \\
11 \\
12 \\
11\end{array}$ & $\begin{array}{l}87 \\
83 \\
83 \\
36\end{array}$ & & \\
\hline & Total & 51 & 289 & & \\
\hline
\end{tabular}

*After adjustment for four periods of year of hire $(<1955,1955-64,1965-74, \geqslant 1975)$.

Increase in risk per unit change in exposure level. The three levels are coded 1,2 , or 3 and the variable is treated as continuous.

†ORs for the year of hire variable were as follows: < 1955, OR = 1.0; 1955-64, OR = 1.56 (95\% CI 0.75 to 3.25$) ; 1965-74$, OR $=0.84$ (95\% CI 0.35 to 2.04$) ; \geqslant 1975, \mathrm{OR}=0.35(95 \% \mathrm{CI}=0.04$ to 2.91$)$.

job details were assumed to be relevant for earlier periods of employment. There are nonsignificant negative trends of risk with levels of cumulative exposure. A higher proportion of cases were in the unclassifiable group; the difference was not significant.

Table 4 shows ORs for brain cancer by levels of cumulative exposure to electromagnetic fields received in the five years before the case diagnosis. The analysis is based on a subset of the data (see methods section). There are nonsignificant negative trends of risk with levels of cumulative exposure. A higher proportion of cases were in the unclassifiable group; the difference was not significant.

Tables 2-4 show the trend analyses (without adjustment for year of hire) which were repeated with additional adjustment for each of 24 potential confounders (table 1) -that is, the potential confounders were considered singly rather than all together. Each study subject was classified in terms of never exposed or possibly exposed in at least one job, or exposed in at at least one job to each of the potential confounders. No indication of a positive trend of risk of brain cancer with level of exposure to electromagnetic fields approached significance. There was no significant association between the risk of brain cancer and exposure to any of the potential confounders.

\section{Discussion}

The results of this study do not show an association between occupational exposure to power frequency magnetic fields and the risk of brain cancer. Although the study population is large, the study has several limitations. These are the problem of unclassifiable cases and controls, the limited exposure data with overlapping values for different job categories, and the gaps in knowledge of employment history. Increased ORs were found for the unclassifiable category but a thorough review of the available data for the unclassifiable cases found no indication that any particular kind of employment was overrepresented in this category nor any evidence to suggest that these people were a biased group. The group is, unfortunately, rather large but the increased ORs are, in the main, not significantly increased. In the absence of other explanations, chance would seem to be the most likely explanation for these increased ORs.

The details of employment history were difficult to define with any accuracy, and were not universally available for employment in the industry before 1972. Nevertheless, full employment details were available for $20 \%$ of the cohort. This group was shown to have very limited job movements and there is no reason to think that this subset is different in job experience from the rest. Anecdotal information from long serving employees supported the assumption that the whole cohort moved job infrequently within or between industries. Exposure assessments are based on limited surrogate measurements taken during the period 1989-93; historical data were not available. Also, the figure shows that there are large variations in exposure within a job group leading to unavoidable overlap in exposures between the job groups. Even if these assessments were clearly delineated they will almost certainly mask important differences in real exposures; it is known that not only is there variation between jobs but also within and between workers within the same job. Overlap in exposure levels might have been reduced if the workers were grouped, for example, by the combination of job group and site. ${ }^{14}$ However, as the total number of sites in the cohort was much larger than the number of sites from which exposure measurements were available, insufficient exposure data were available for such a classification scheme.

Grouping workers into different exposure categories with different time windows is somewhat arbitrary and varies between the published studies. Unfortunately, there is no consensus on the best way to avoid misclassification, although the choice of cut off point could well influence the ORs, particularly in the highest exposure categories. ${ }^{15}$ Also, there is no agreement on the most appropriate exposure metric for electromagnetic fields. It is possible that other groupings such as percentage of time above a particular level or even the square of the exposure measured might be computed. The analyses here were restricted to those that could be compared with other studies. In this study, periods have also been 
chosen for comparason with previously published work, in particular that of Theriault et $a l .{ }^{6}$ This device in some measure, answers the question of tumour promotion and excludes the subjects over 70 years old in one analysis. In the present study, the exposure assessments are fewer than those found in the Southern Californian Edison, ${ }^{5}$ the Canada France, ${ }^{6}$ and the United States Electric Utility ${ }^{7}$ studies and are based on lower values. Confounding seems not to be a major problem in the current study, but in all these studies, assessments of confounding exposures are crude or insensitive. It is difficult to judge whether these assessments are accurate or not.

Finally, the studies used different disease outcome measures. This study used histologically confirmed diagnosis of primary brain cancer. In many studies, it is unclear whether secondary brain tumours have been satisfactorily excluded from the cases included in the analysis. If exposure to electromagnetic fields were to cause primary, but not secondary, brain cancer, misclassification of secondary tumours would tend to dilute any effect of exposure to electromagnetic fields.

We have looked again at the publications on the suggested association between risk of brain cancer and exposure to electromagnetic fields. It includes several reports with substantial increases in risk. ${ }^{21617}$ These studies were based on occupations cited on death certificates. Most studies that rely on employer's job title as a surrogate for exposure show only modest relative risks of $1 \cdot 2$ to $2 \cdot 0 .^{3}$

The more recent studies have used more refined methods. ${ }^{4-71819}$ They are based on large cohorts of workers in relevant industries and in which some assessment of exposure has been made with measurements of magnetic fields on current employees extrapolated to provide estimates of cumulative exposure.

The case control study of Swedish men by Floderus et $a l^{4}$ found no consistent patterns for exposure to magnetic fields and brain cancer although the ORs were increased in the two highest quartiles for median exposure and there was a suggestion of a dose-response for time exposed above $0.20 \mu \mathrm{T}$. The authors reanalysed the data in 1994 by dividing the study period into two and concentrating on railway workers. ${ }^{18}$ Brain cancer ORs approximated to unity.

The cohort of 36221 workers at Southern Californian Edison reported by Sahl et $a l^{5}$ included nested case control studies, one of which centred on brain cancer. No consistent association was found between assessments of magnetic fields and brain cancer. The smaller study of 5088 employees of eight Norwegian power companies by Tynes et al ${ }^{19}$ also showed no association.

Savitz and Loomis ${ }^{7}$ studied a large cohort (138 905 male employees) of five United States electric utilities which included 151 deaths from brain and central nervous system tumours. The information on diagnosis seems to rely entirely on data from death certificates. Brain cancer was weakly associated with duration of work in exposed jobs. The association was stronger for cumulative exposure to magnetic fields with a relative risk of $1.94 / \mu \mathrm{T}$.y for exposure two to 10 years before death and a mortality ratio of $2 \cdot 6$ for exposure levels $>0.7 \mu \mathrm{T}$ within that two to 10 year period.

Finally, the Canada-France study by Thériault et $a l^{6}$ included 223200 employees yielding 60 cases of brain cancer with a better confirmation of diagnosis than that of Savitz and Loomis ${ }^{7}$ : ORs for exposures above the median exposure ( $3 \cdot 1 \mu \mathrm{T}$ years) and above the 90th percentile $(15.7 \mu \mathrm{T} . \mathrm{y})$ were not significantly increased at 1.57 and 1.95 respectively. For astrocytoma the OR for exposures above the 90th percentile was significant but was based on only five cases.

Overall, these large, well designed studies do not provide a persuasive case for a causal link between occupational exposure to magnetic fields and the risk of brain cancer even though many of the methodological shortcomings of earlier studies have been at least partially overcome. ${ }^{20}$ Nevertheless, Kheifets et $a{ }^{21}$ in a meta-analysis of studies of electromagnetic fields and brain cancer, conclude that for the studies with the best exposure characterisation there is a modest increase in risk. They suggest that there is some evidence of trend in risk with the lowest exposure category 1.23 (95\% CI 1.06 to 1.42$)$ to highest 1.61 ( $95 \%$ CI 1.23 to 2.04$)$. The ORs in our study are below this range but the confidence intervals overlap with those cited by Kheifets $e t$ al.

If further studies of this type are to contribute to scientific knowledge it is clear that very large cohorts are required, exposure assessments will need even more refining (and preferably include study populations with a wider range of exposures), and histological confirmation of diagnoses will be essential.

We gratefully acknowledge the financial support of the successor companies of the Central Electricity Generating Board, in particular the National Grid Company, in carrying out this study. Also we thank staff of the successor companies for their assistance, in particular Dr B Maddock and Dr D C Renew (National Grid Company), Mr P Brodie and Dr G A Harte (Nuclear Electric), and Mr R Nye (PowerGen). Thanks are also due to staff of the Department of Social Security, Newcastle upon Tyne and the Office of Population Censuses and Surveys for their assistance in following up the study population.

1 Milham S. Mortality from leukaemia in workers exposed to electric and magnetic fields. N Engl F Med 1982;307:249.

Lin RS, Dischinger PC, Conde J, Farrell KP. Occupational exposure to electromagnetic fields and the occurrence of brain tumours. $\mathcal{F}$ Occup Med 1985;27:413-9.

3 National Radiological Protection Board. Electromagnetic fields and the risk of cancer: report of an advisory group on non-ionising radiation. Chilton, Oxfordshire: NRPB, 1992:1-138. (Doc NRPB 3 No 1.)

4 Floderus B, Persson T, Stenlund C, Wennberg A, Ost A, Knave B. Occupational exposure to electromagnetic fields in relation to leukaemia and brain tumours. A casecontrol study in Sweden. Cancer Causes Control 1993;4: 465-76.

5 Sahl JD, Kelsh MA, Greenland S. Cohort and nested case control studies of haemopocitic cancer and brain cancer among Electric Utility Workers. Epidemiology 1993;4: 104-14.

6 Thériault G, Goldberg M, Miller AB, Armstrong B, Guenel P, Deadman J, et al. Cancer risks associated with occupational exposure to magnetic fields among electric utility workers in Ontario and Quebec, Canada, and France: 1970-89. Am $¥$ Epidemiol 1994;139:550-72.

7 Savitz DA, Loomis DP. Magnetic field exposure in relation to leukaemia and brain cancer mortality among electric to leukaemia and brain cancer mortality among

8 National Radiological Protection Board. Electromagnetic fields and the risk of cancer. Report of the advisory group fields and the risk of cancer. Report of the advisory group
on non-ionising radiation. NRPB, 1997 (in press). (Doc NRPB 7.) 
9 Merchant CJ, Renew DC, Swanson J. Occupational exposure to power frequency magnetic fields in the electricity supply industry. Fournal of Radiological Protection 1994; 14:155-64.

10 Merchant CJ, Renew DC, Swanson J. Exposures to powerfrequency magnetic fields in the home. Fournal of frequency magnetic fields in the
Radiological Protection 1994;14:77-87.

11 International Agency for Research on Cancer. Monographs on the evaluation of carcinogenic risks to humans 1972-1995. Lyon: IARC, 1995:1-60.

12 Hartman DE. Neuropsychological toxicology. Identification and assessment of human neurotoxic syndromes. New York: Pergamon Press, 1988.

13 Breslow NE, Day NE. Statistical methods in cancer research Vol II. The design and analysis of cohort studies. Lyon: International Agency for Research on Cancer, 1987. (IARC Sci Publ No 82.)

14 Kromhout H, Loomis DP, Mihlan CJ, Peipens LA Kleckner RC, Iriye R, Savitz DA. Assessment and grouping of occupational magnetic field exposure in five elecing of occupational magnetic field exposure in five electric utility compar;21:43-50.

15 Delpizzo V, Borghesi JL. Exposure measurement errors, risk estimate and statistical power in case control studies using dichotomous analysis of a continuous exposure variable. Int f Epidemiol 1995;24:851-62.

16 Speers MA, Dobbins JG, Miller VS. Occupational exposure and brain cancer mortality: a preliminary study of sure and brain cancer mortality: a preliminary study
east Texas residents. $A m \mathcal{F}$ Ind Med 1988;13:629-38.

17 Thomas TL, Stolley PD, Stemhagen A, Fontham ETH, Bleeker ML, Stewart RA, Hoover RN. Brain tumour mortality risk among men with electrical and electronic jobs. A case control study. F Natl Cancer Inst 1987;79: 223-8.

18 Floderus B, Tornqvist S, Stenlund C. Incidence of selected cancers in Swedish railway workers 1961-79. Cancer Causes Control 1994;5:189-94.

19 Tynes T, Reitan JB, Anderson A. Incidence of cancer among workers in Norwegian hydroelectric power companies. Scand $\mathcal{F}$ Work Environ Health 1994;20:339-44.

20 Savitz DA, Pearce N, Poole C. Update on methodological issues in the epidemiology of electromagnetic fields and cancer. Epidemiol Rev 1993;15:558-66.

21 Kheifets LI, Afifi AA, Buffler P, Zhang ZW. Occupational electric and magnetic fields exposure and brain cancer: a meta-analysis. f Occup Environ Med 1995;37:1327-41.

\section{Occupational and Environmental Medicine and the electronic age}

OEM has an Email address which is 100632.3615@compuserve.com. We welcome contact by Email, including letters to the editor. Some of our reviewers already send us their reports by Email, helping to speed up the peer review process.

We are moving towards electronic publishing and for some months now we have been asking authors to send us their revised papers on disk as well as a hard copy. I am delighted to report that nearly all our authors are managing to comply with this request. Oddly enough, the few authors who have not sent us a disk version of their revised papers have been almost exclusively from the United Kingdom. I would be interested in suggestions for why this might be. Perhaps United Kingdom based authors read our correspondence and instructions less assiduously? Watch for revised Instructions to Authors.

The Editor 